
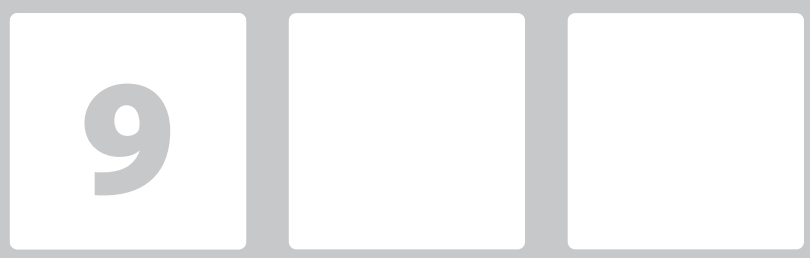

\title{
GESTÃO DE PROCESSOS DE COMUNICAÇÃO EM INSTITUIÇÕES FEDERAIS DE ENSINO SUPERIOR: UM ESTUDO DE CAMPO NA UNIVERSIDADE FEDERAL DE SANTA MARIA
}

\section{Communication Process Management in Federal Universities: A Field Study in Federal University of Santa Maria}

\section{Sendi Chiapinotto Chiapinotto Spiazzi}

Universidade Federal de Santa Maria (UFSM)

email:sendi.rp@gmail.com

\section{Luciana Flores Battistella}

Universidade Federal de Santa Maria (UFSM)

email: luttibattistella@gmail.com

\section{RESUMO}

Este estudo tem por objetivo propor melhorias nos processos de comunicação da Universidade Federal de Santa Maria. Como referencial teórico, são utilizadas as perspectivas da comunicação pública apresentadas por Brandão (2012): Comunicação Organizacional; Comunicação Científica; Comunicação do Estado e/ou Governamental. Além disso, a gestão por processos é trabalhada sob a ótica da Association of Business Process Management Professionals (ABPMP, 2009) e as técnicas de identificação de necessidades de melhorias em processos 5W2H, Método de Análise e Solução de Problemas (MASP). Como opção metodológica, utilizam-se a pesquisa bibliográfica e o estudo de campo, com análise documental, pesquisa participante, entrevistas semiestruturadas e checklist. Os resultados apontam a possibilidade de informatização do processo de atualização do site/portal da Universidade e a proposta de algumas melhorias como: construção de um Guia de Produção de Conteúdo; treinamentos e reuniões de pauta periódicas; campanhas de valorização da comunicação pública e de popularização da ciência.

Palavras-chave: Comunicação Pública; Comunicação Institucional; Gestão de Processos; Instituições Federais de Ensino Superior; Universidade Federal de Santa Maria.
This study aims to propose improvements in the communication processes of Federal University of Santa Maria. As a theoretical reference, the paper presents the public communication perspectives by Brandão (2012): Organizational Communication; Scientific Communication; State/Government Communication. In addition, process management is handled from the viewpoint of Association of Business Process Management Professionals (ABPMP, 2009) and techniques for identifying process improvement needs such as $5 \mathrm{~W} 2 \mathrm{H}$, Analysis and Problem Solving Method. As a methodological option, bibliographic research and field study, with documentary analysis, participant research, semi-structured interviews and checklist are used. The results point out the need to computerize the process of the University's website/portal updating and the proposal of some improvements such as the construction of a Content Production Guide, periodic training and meetings, campaigns for enhancement of public communication and popularization of science.

Keywords: Public Communication Processes; Institutional Communication; Process Management; Universities; Federal University of Santa Maria. 


\section{INTRODUÇÃO}

$\mathrm{Na}$ atual conjuntura política e socioeconômica do Brasil, as instituições públicas, em especial as universidades, têm sofrido com a imagem da ineficiência do serviço público. O ensino superior federal teve uma recente e expressiva expansão com o Programa de Apoio a Planos de Reestruturação e Expansão das Universidades Federais (Reuni), porém desde 2015 sofre com a redução de verbas, interferências na autonomia universitária, além de críticas sobre sua real contribuição à sociedade por meio do ensino, pesquisa e extensão.

A comunicação pública cumpre o papel de divulgar o conhecimento produzido nestas instituições e construir seu relacionamento com a sociedade:

Ações e discursos estratégicos sobre temas de Interesse Público configuram o espaço da comunicação pública, constituído a partir da circulação desses temas abordados por diferentes sistemas de comunicação estruturados nas instituições públicas e privadas (WEBER, 2007, p. 22).

Silva (2014), por meio de pesquisa realizada no Instituto Federal de Santa Catarina (IFSC), observou que uma das formas de tornar eficiente a comunicação de uma IFES é construindo um sistema de comunicação efetivo, capaz de promover a unicidade da organização, divulgar externamente o que ela pode oferecer à sociedade e consolidar sua imagem. No estudo, a abordagem utilizada pelo autor para melhorar a eficiência e alinhar os fluxos de comunicação organizacional foi o mapeamento e a proposição de melhorias de processos de comunicação - a partir da abordagem de gerenciamento de processos - além de uma sugestão de reestruturação da área.

Já a abordagem por processos é utilizada por diversos autores como forma de modernizar e alinhar os fluxos e processos de trabalho na administração pública, substituindo o velho modelo de administração patrimonialista-burocrática que não considerava as necessidades e a satisfação dos cidadãos em seus processos de trabalho. Em seu estudo no Governo de Minas Gerais, Ferreira et al. (2014, p. 23) destacam a “importância do Gerenciamento de Processos para a melhoria contínua das organizações públicas e das contribuições advindas da adequada utilização das ferramentas para tal gerenciamento".
Na Universidade Federal de Santa Maria (UFSM), local de análise deste estudo de campo, não é diferente do IFSC. A partir do Plano de Desenvolvimento Institucional (PDI), da construção da Política de Comunicação da Universidade e do mapeamento de processos de comunicação, identificou-se uma descentralização da comunicação e a falta de diretrizes comuns e de macroprocessos de comunicação institucional definidos, tais como: campanhas de comunicação interna, assessoria de imprensa, organização de eventos e atualização de sites e mídias sociais.

Por isso, entendendo que para tornar a comunicação das IFES mais eficiente perante a sociedade, na perspectiva da comunicação pública e utilizando-se da filosofia de gestão por processos para alinhar as práticas comunicacionais, tem-se como problema de pesquisa: Como melhorar os processos de comunicação de uma IFES considerando as perspectivas da comunicação pública? Para responder tal questão, coloca-se como objetivo geral deste trabalho propor melhorias nos processos de comunicação da UFSM, o que pode também servir para os setores de comunicação de outras IFES que enfrentam problemas similares. Como objetivos específicos da pesquisa, tem-se: identificar os processos de comunicação já mapeados na UFSM; ampliar o mapeamento do processo de atualização portal/site a partir da perspectiva de outros setores da comunicação da Universidade; identificar gargalos e nós nos fluxos de informação e comunicação entre os setores, propondo melhorias no processo alinhadas à Política de Comunicação da instituição e às perspectivas da comunicação pública;

Para tanto, foi escolhido o processo de produção de conteúdo e atualização do site, por ser um processo comum em diversas IFES, contar com a participação de diversos setores de comunicação da Universidade e com a participação da comunidade acadêmica no envio e consumo do conteúdo publicado.

A pesquisa justifica-se, pois há poucos estudos que conectam a comunicação e a administração pública, principalmente no âmbito das instituições federais de ensino superior. Além disso, o momento é oportuno para o mapeamento e propostas de melhorias nos processos de comunicação da UFSM, uma vez que a gestão por processos tem sido trabalhada na administração central da Universidade desde 2017. O 
recente lançamento da Política de Comunicação da UFSM, por meio da Resolução 05/2018, propondo duas novas estruturas formais de comunicação: Unidade de Comunicação Integrada e Comitê da Política de Comunicação também demonstra que o setor está aberto para mudanças e melhorias em suas práticas.

Portanto, acredita-se que este trabalho, além de contribuir cientificamente na convergência dos estudos de administração (pública) e comunicação (pública), também terá uma contribuição prática no fazer comunicacional da UFSM e de outras IFES, uma vez que a autora atua na área de comunicação desta Universidade.

\section{COMUNICAÇÃO PÚBLICA}

A comunicação pública é considerada pelos principais autores brasileiros um conceito em construção que ainda gera muitas reflexões, principalmente no intuito de diferenciar a comunicação realizada entre Estado e cidadão, a comunicação governamental, a política, a institucional e a de interesse público. Weber (2007, p. 24) sinaliza bem esse panorama complexo do conceito de comunicação pública quando descreve:

\begin{abstract}
Comunicação pública é um conceito confortável porque sua liquidez serve a diferentes abordagens teóricas e sua complexidade só aparece no momento de sua exequibilidade. Insubstituível, tornou-se o termo utilizado pelas habilitações do campo comunicacional (relações públicas, marketing, jornalismo, comunicação), no sentido de entender ou justificar as interferências e a delimitação entre o público e o privado, entre a comunicação governamental e a política, a comunicação do terceiro setor e a sociedade, o marketing e a propaganda, etc. Especialmente quando se discute sistemas de comunicação, mídias, cuja criação e funcionamento dependem do Estado,
\end{abstract}

governos, legislativos, sociedade e organizações diversas (WEBER, 2007, p. 24).

Um dos primeiros teóricos do tema, o francês Pierre Zémor (2009, p. 189) afirma que comunicação pública

\begin{abstract}
É troca e compartilhamento de informações de utilidade pública ou de compromissos de interesses gerais. Ela contribui para a conservação dos laços sociais. A responsabilidade disso compete às instituições públicas; ou seja, às administrações do Estado, aos serviços das coletividades territoriais, aos estabelecimentos, empresas, organismos encarregados de cumprir uma missão de interesse coletivo (ZÉMOR, 2009, p. 189).
\end{abstract}

Ainda para Zémor (2009), ao considerar os interesses coletivos, impõe-se uma transparência dos procedimentos e decisões por meio do diálogo e da fé no debate público. A partir da participação dos cidadãos é que podem surgir soluções. Brandão (2012, p. 6) também coloca a comunicação pública como aliada à cidadania ao afirmar que essa "diz respeito a um processo comunicativo que se instaura entre o Estado, o governo e a sociedade com o objetivo de informar para a construção da cidadania”. A mesma autora propõe uma categorização mais ampla, apresentando cinco perspectivas para a comunicação pública no Brasil, conforme apresentado no Quadro 1.

Diante disso, trazendo para o âmbito das instituições federais de educação superior (IFES), este trabalho adota a comunicação pública sob as perspectivas: Organizacional (uma vez que contempla todo tipo de organização na sua relação com os públicos); do Estado e/ou Governamental (por se tratarem de autarquias federais); Científica (por se tratarem de instituições de educação alicerçadas no tripé ensino,

Quadro 1 Perspectivas de comunicação pública no Brasil

\begin{tabular}{l|l}
\hline \multicolumn{1}{c|}{ Perspectiva } & \multicolumn{1}{c}{ Descrição } \\
\hline Comunicação Organizacional & $\begin{array}{l}\text { Da instituição/empresa com seus públicos para o fortalecimento da imagem organizacio- } \\
\text { nal. }\end{array}$ \\
\hline Comunicação Científica & Por meio da popularização do conhecimento científico para o desenvolvimento do país. \\
\hline Comunicação do Estado e/ou Governamental & Das instituiçães públicas com os cidadãos, visando ao debate público. \\
\hline Comunicação Política & Busca defender ideias e posicionamentos políticos. \\
\hline Comunicação Comunitária e/ou Alternativa & Caracterizada pelas estratégias comunicacionais da sociedade civil organizada. \\
\hline
\end{tabular}

Fonte elaborado pelas autoras (2018) com base em Brandão (2012). 
pesquisa e extensão). Essas perspectivas são aprofundadas no quadro 1.

A partir das três primeiras perspectivas, comuns em instituições federais de ensino superior, este trabalho busca propor melhorias no processo de atualização e produção de conteúdo para o site institucional da UFSM. Para tanto, faz-se necessário abordar o gerenciamento por processos.

\section{GERENCIAMENTO POR PROCESSOS}

De acordo com estudos realizados pelo Instituto de Pesquisa Econômica Aplicada (BRASIL, 1996b), a metodologia de Gestão por Processos é uma das filosofias utilizadas para a otimização e o aumento de agilidade nos serviços prestados pelo setor público brasileiro. Conforme explicita Gonçalves (2000, 2000a), as estruturas tradicionais, típicas das organizações baseadas em funções como as instituições públicas, possuem dificuldade de enxergar os processos como um todo, uma vez que suas atividades são organizadas de forma fragmentada. Por isso, uma visão mais horizontal de gestão por processos é uma forma diferente de trabalhar a agilidade e a eficiência dos serviços prestados nessas organizações.

Para tratar de gerenciamento de processos em instituições públicas ou privadas, é importante compreender o que são processos. Processo "é uma ordenação específica das atividades de trabalho no tempo e no espaço, com um começo, um fim, inputs e outputs claramente identificados: uma estruturação para a ação" (DAVENPORT, 1994, p. 7).

Mello et al. (2006) apontam que a gestão por processos consiste em uma metodologia para a contínua avaliação, análise e melhoria dos processos centrais da organização, ou seja, aqueles que mais influenciam na satisfação dos públicos. Para a Association of Business Process Management Professionals (ABPMP2009), a gestão por processos é uma abordagem de gestão que busca identificar, desenhar, executar, documentar, monitorar, controlar e melhorar os processos de uma instituição com o objetivo de criar valor, alcançar resultados pretendidos e alinhados às metas estratégicas.
Dentro da filosofia de gerenciamento por processos, uma das abordagens possíveis é a de melhoria e mudança de processos, a qual compreende práticas para otimizar, inovar e redesenhar processos de negócio existentes e previamente analisados (SMART et al., 2009; VALLE \& OLIVEIRA, 2009). A melhoria de processos (BPI - Business Process Improvement), para a ABPMP (2009, p. 236), "é uma iniciativa específica ou um projeto para melhorar o alinhamento e o desempenho de processos com a estratégia organizacional e as expectativas do cliente", no caso de instituições públicas, as expectativas dos cidadãos e da sociedade de forma geral.

No mapeamento, utilizam-se técnicas de análise do processo que, de acordo com Mello et al. (2006), permitem diagnosticar falhas e oportunidades de melhoria, como gargalos e retrabalhos. O mapeamento de processos desempenha um papel relevante para o entendimento do fluxo de trabalho, de forma a avaliar sua eficiência, eficácia e efetividade.

Considerando os conceitos de comunicação pública e gestão por processos apresentados, bem como as pesquisas realizadas nos últimos anos sobre as realidades das IFES, têm-se que os processos de comunicação são complexos e fluídos, não estanques. Tratando-se de processos de comunicação pública, eles visam à discussão de temas de interesse público e o diálogo com o cidadão. Ainda ajustando o foco nos processos de comunicação pública em IFES, os fluxos de informação devem sempre ir além da transparência e do relacionamento com a sociedade, buscando compartilhar e construir conhecimento, melhorando a qualidade de vida a partir das atividades de ensino, pesquisa e extensão.

\section{PROCEDIMENTOS METODOLÓGICOS}

O método adotado é o estudo de campo que, de acordo com Gil (1999), é uma categoria de pesquisa que busca descrever uma realidade específica e a interação entre os integrantes de um grupo inserido nesta realidade. Quanto aos procedimentos, primeiramente, foi realizada uma pesquisa documental em diversos documentos da UFSM, entre eles o Regimento Interno (UFSM, 2011); o Plano de Desenvolvimento 
Institucional 2016-2026 (UFSM, 2016) e a Política de Comunicação (UFSM, 2018). O objetivo foi descrever o que rege formalmente a comunicação na instituição. Além disso, foram analisados os processos mapeados pelo Grupo de Modernização Administrativa junto à Coordenadoria de Comunicação da Universidade, com foco no processo de Atualização do portal/site da UFSM. Para realizar a descrição dos setores e suas funções e analisar os processos mapeados, além da análise documental, foi realizada uma pesquisa participante da dinâmica comunicacional da instituição por meio da participação em grupos de trabalho para implementação da Política de Comunicação e Reestruturação do portal e sites institucionais.

Com base nos dados levantados e observados, foram conduzidas, de setembro a outubro de 2018, entrevistas semiestruturadas com sete profissionais de comunicação de um universo de 26 profissionais da instituição analisada. Entre os sete escolhidos, estão dois jornalistas da Agência de Notícias (setor responsável pelo site e mídias sociais da Universidade) e outros cinco profissionais que atuam no Gabinete do Reitor, centros de ensino e campi fora de sede. A entrevista foi estruturada a partir de quatro dimensões: 1) Comunicação Pública na UFSM; 2) Mapeamento do processo de atualização de sites; 3) Tomada de decisão para outros processos que envolvem produção de conteúdo, como atualização de mídias sociais e assessoria de imprensa; 4) Identificação de problemas e possíveis soluções.

Para o redesenho e proposta de melhorias nos processos, foi utilizada a metodologia $5 \mathrm{~W} 2 \mathrm{H}$ (BASTOS, 2013) que consiste em uma série de questionamentos que busca registrar detalhes do processo antes de propor melhorias. Os cinco Ws (do inglês) referem-se a What (O quê?), When (Quando?), Why (Por quê?), Where (Onde?) e Who (Quem?). Os $2 \mathrm{Hs}$ correspondem às palavras How (Como?) e How Much (Quanto?). Outro método de melhoria que inspirou esta análise é o Método de Análise e Solução de Problemas (MASP), que identifica os problemas; localiza as causas fundamentais dos problemas encontrados; desenvolve e programa ações corretivas e consolida as melhorias obtidas. Os questionamentos necessários a essas duas metodologias foram inseridos na quarta dimensão da entrevista aplicada.

\section{APRESENTAÇÃO E ANÁLISE DOS RESULTADOS}

Este estudo de campo tem como local de análise a Universidade Federal de Santa Maria (UFSM), criada em 14 de dezembro de 1960, a partir da união de diversos cursos superiores existentes em Santa Maria. Sua criação fez parte de um grande movimento em prol da interiorização do ensino universitário no país. Foi a primeira universidade federal do Brasil instalada fora do eixo das capitais (BARICHELLO, 2000). Em maio de 2018, ofertava 132 cursos de graduação, 105 de pós-graduação, cinco de nível médio e 27 de ensino pós-médio'.

Uma instituição pública do porte da UFSM, com sua comunidade acadêmica estimada em mais de 35 mil pessoas - entre estudantes, docentes e servidores técnico-administrativos, - e distribuída em quatro campi - Santa Maria, Frederico Westphalen, Palmeira das Missões e Cachoeira do Sul - e inúmeras unidades e subunidades, incluindo uma em Silveira Martins, possui uma produção de conteúdo diária e incontáveis pontos de contato e relacionamento com seus públicos. Porém, a estrutura de comunicação da Universidade apresenta dificuldade em atender todas as unidades e públicos, o que gera iniciativas de comunicação descentralizadas e sem um alinhamento institucional, além de impasses na definição de fluxos e diretrizes.

A atual Coordenadoria de Comunicação Social foi instituída em 1998, ligada ao Gabinete do Reitor (UFSM, 1998). Atualmente, o setor abrange a Rádio Universidade AM, a Rádio UniFM (lançada em 2018), a TV Campus e a Agência de Notícias - responsável pelo site, mídias sociais digitais, assessoria de imprensa e pela Revista Arco (jornalismo científico e cultural). Em 2016, foram institucionalizados os Núcleos de Divulgação Institucional localizados nos Centros Ensino e nos campi fora de sede, com atuação de profissionais não necessariamente formados em comunicação e estudantes da Relações Públicas. Em 2018, a UFSM lançou sua Política de Comunicação, criando também a Unidade de Comunicação Integrada e o Comitê de Política de Comunicação.

É importante apresentar o que os documentos oficiais da Universidade regem sobre a estrutura es 
processos comunicacionais da instituição. Iniciando pelo Estatuto da Universidade, atualizado de acordo com a Portaria $n^{\circ} 156 / 2014$, um dos objetivos fundamentais da UFSM é "transmitir o saber por meio do ensino, de publicações e/ou de outras formas de comunicação" (UFSM, 2014, p. 4). O Estatuto deixa bem claro o papel de comunicação científica da Universidade.

O Regimento Interno da UFSM, aprovado pelo Parecer 031/2011 da Comissão de Legislação e Regimentos do Conselho Universitário e pela Resolução $n^{\circ}$ 006/2011, prevê em seu Art. 25 a Coordenadoria de Comunicação Social como órgão executivo da administração superior que, de acordo com o Art. 31, compete:

\footnotetext{
I - executar os serviços de rádio, televisão, comunicação institucional e produção de notícias;

II - estabelecer a política global de comunicação para a Instituição;

III - facilitar a ação dos veículos de comunicação na busca de informações sobre a Universidade e manter constante relacionamento com a imprensa local, regional e nacional; IV - dar apoio aos eventos científicos, educacionais e culturais que se realizem na Instituição; e

$\mathrm{V}$ - informar a sociedade sobre os fatos e acontecimentos ocorridos na UFSM (UFSM, 2011, p.13).
}

O Plano de Desenvolvimento Institucional (PDI) 2016-2026 é o Planejamento Estratégico da UFSM. O documento cita a necessidade de aumentar a eficiência do processo de comunicação institucional, considerando a acessibilidade para pessoas com deficiência. Também prevê a "melhoria da comunicação institucional, como forma de melhor divulgar o conhecimento produzido na instituição" (UFSM, 2016, p. 111). Algumas das contribuições da comunidade universitária neste aspecto são "desenvolver plano de comunicação institucional que promova a comunicação administrativa, interna, institucional e mercadológica" e "buscar a estruturação de um setor de comunicação por campi” (UFSM, 2016, p. 120).

Em 2018, a Política de Comunicação foi lançada na Universidade. Ela prevê como objetivos da área de Comunicação da UFSM:

I. promover o diálogo entre instituição e seus variados públicos;

II. dar visibilidade às suas ações de ensino, pesquisa e extensão;
III. buscar legitimidade institucional perante a sociedade; IV. reconhecer, fomentar e tornar visível o capital intelectual e social da Instituição em prol do desenvolvimento da sociedade; V. profissionalizar a atividade de Comunicação da UFSM (UFSM, 2018).

Além disso, a Política prevê como princípios de Comunicação o interesse público; o diálogo; a transparência; a pluralidade; a integração da Comunicação Pública às atividades de ensino, pesquisa e extensão da UFSM; a sustentabilidade e a acessibilidade.

Quanto à gestão de comunicação da Universidade, a Política (UFSM, 2018) reconhece institucionalmente:

- Unidades de Assessoramento Institucional e de Gestão - representado pelos Núcleos de Divulgação Institucional das Unidades Universitárias e Assessoria de Comunicação do Gabinete do Reitor - conta com 21 servidores;

- Unidades de Produção Pedagógica - equivalente aos laboratórios e atividades relacionadas aos Departamentos de Ciências da Comunicação (campi Santa Maria e Frederico Westphalen) e seus cursos de Jornalismo, Relações Públicas, Publicidade e Propaganda e Produção Editorial - conta com 63 servidores, entre professores e técnicos;

- Unidades de Produção e Veiculação de Conteúdos - ou seja, a Coordenadoria de Comunicação e seus núcleos de Rádios (Universidade AM e UniFM), TV Campus e Agência de Notícias conta com 34 servidores;

- Unidade de Comunicação Integrada - criada com a aprovação da Política de Comunicação para garantir a articulação entre os setores e o planejamento de comunicação da Universidade - conta com três servidores;

- Áreas Convergentes - outras áreas da Universidade que contribuem com a comunicação, como: Sistemas de Informação; Acessibilidade; Documentação; Internacionalização; Departamentos de Desenho Industrial e Turismo; Educação a Distância; Transparência e Acesso à Informação; Coordenadoria de Cultura e Apoio a Eventos da Pró-reitora de Extensão; Imprensa Universitária e Ciência da Informação. 
A partir das perspectivas governamental, institucional e científica da comunicação pública, da análise dos documentos institucionais da UFSM e de sua estrutura, o processo escolhido para ser analisado neste estudo foi a Atualização do portal/site da UFSM, sob responsabilidade da Agência de Notícias, visando ampliar seu mapeamento, identificar problemas e propor melhorias nos fluxos desse processo. É o processo mais comum de comunicação em todas as IFES. Além disso, é um dos mais completos, uma vez que conta com a participação de todos os públicos para envio, consumo e feedback de informações, desde estudantes e servidores até a comunidade externa.

Para isso, além de análise documental, foram aplicadas sete entrevistas semiestruturadas com profissionais da Agência de Notícias e dos Núcleos de Divulgação Institucional (Unidades de Assessoramento e Gestão, de acordo com a Política) durante os meses de setembro e outubro de 2018. As questões iniciais da entrevista reafirmam a importância desse processo na estrutura e na prática da comunicação pública na instituição.

Quando questionados sobre as prioridades de comunicação da UFSM, muitas questões são citadas, entre elas, a comunicação institucional, a transparência, a divulgação científica e a produção de conteúdo para o portal/site da UFSM:

A comunicação, a produção de conteúdo que ela faz a partir do site hoje é um dos principais meios de comunicação que a Universidade tem para com os alunos, servidores, professores e também públicos em potencial que seriam, por exemplo, os potenciais alunos, os potenciais servidores, pessoas que estão procurando concursos. Então ele é um dos principais meios. E o site, a partir daí a gente tem uma comunicação que se dá por notícias ou também que se dá a partir até mesmo de eventos, editais, vídeos e áudios (Trecho de entrevista com Jornalista 2).

Partindo para a análise do processo de atualização/produção de conteúdo para o site/portal, utilizou-se as técnicas de diagnóstico 5W2H e MASP. O Jornalista 2 explica a rotina de recebimento de demandas por conteúdo:

A rotina foi estruturada durante muito tempo a partir dos e-mails. Existiam dois formulários no site "Mande sua notícia" e "Divulgue seu evento" e, para além disso, as notícias eram encaminhadas pelo e-mail. Então, muito do processo da publicação de notícias e eventos era a partir dali. [...]. Além disso, muita pauta chegava por ligações ou também a partir de reuniões com a Reitoria. Essas pautas vinham a partir da figura da Coordenadora de Comunicação, que é a pessoa que está no organograma acima da Agência, e que participa das reuniões com o reitor e com os pró-reitores. A partir daí, vinham pautas demandadas ou que a Coordenadora enxergava nas reuniões. Tem pautas que são levantadas pela equipe ao observar a rotina da Universidade, pautas levantadas a partir do calendário acadêmico, das reuniões do CEPE [Conselho de Ensino, Pesquisa e Extensão]... entram aí pautas institucionais, grandes eventos (Trecho de entrevista com Jornalista 2).

No Formulário de Mapeamento de Processos, duas tarefas do processo foram registradas: 1) Seleção, edição e publicação de notícias no site institucional da UFSM; 2) Produção de reportagens para o site institucional da UFSM. Como saída do processo, o Formulário descreve a divulgação da notícia. Após a sua publicação no site, o processo pode dar início a outros processos como Atualização das Mídias Sociais e Assessoria de Imprensa (envio de conteúdo para veículos de comunicação externos). Quanto às mídias sociais, o Jornalista 2 afirma que avalia, entre as notícias publicadas no site, o que pode gerar engajamento (curtidas, comentários, compartilhamentos, retweets), pois de acordo com ele, nem tudo o que é de interesse público, pode ser interessante para as mídias sociais. Além disso, cada rede tem critérios específicos para postagem de conteúdo, algumas priorizam textos curtos, outras dependem de fotos ou vídeos.

Quanto à Assessoria de Imprensa, ambos os jornalistas contam que o processo está sendo revisto na Universidade. A Figura 1 apresenta o processo de Atualização do portal/site da UFSM desenhado pelo Grupo de Modernização Administrativa da Universidade.

De acordo com o processo mapeado, a Agência de Notícias recebe publicações por e-mail, por formulário online ou por meio de apuração em outros sites da UFSM; analisa a informação; decide se será publicada no portal. Se sim, edita e publica o texto. A equipe pode ainda produzir reportagens apurando informações a partir de consulta a fontes, análise de documentos e/ou cobertura de eventos. Então, edita e publica a notícia. 
Figura 1 Processo de Atualização do portal/site da UFSM como ocorre atualmente

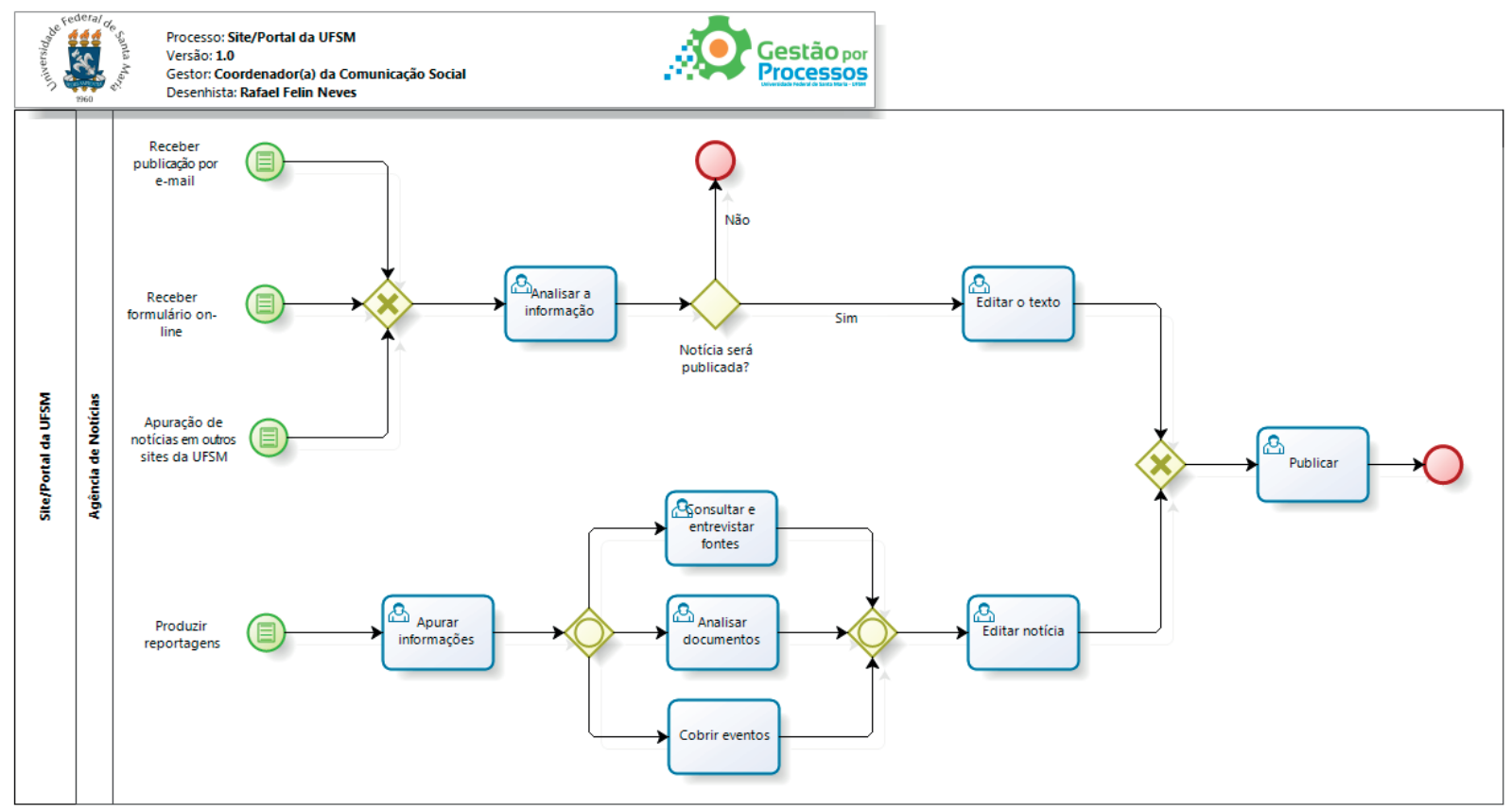

Fonte Elaborada pelo Grupo de Modernização Administrativa da UFSM (2018) no software Bizagi Modeler.

Conforme citado nos inputs do processo, as notícias chegam pelos setores, servidores, estudantes e pelos Núcleos de Divulgação Institucional. De acordo com Marchiori (2008) e Kunsch (2003), é importante que as ações de comunicação sejam planejadas incluindo todos os profissionais de comunicação de uma instituição e todos devem contar a mesma história, por isso um dos objetivos deste trabalho é justamente incluir os Núcleos no mapeamento deste processo, uma vez que eles podem descentralizar o fluxo de informação, facilitando a comunicação com a comunidade universitária. Além disso, os profissionais que atuam nesses setores, alguns formados em Comunicação, atualizam os sites de suas unidades, os quais integram o portal ${ }^{2}$ da UFSM. Para o Jornalista 2 , atualmente, há mais profissionais atuando nesses Núcleos, o que facilita esse diálogo, permite demandar informações e conhecer o que acontece em diversos espaços da Universidade.
Nas Unidades, mesmo as que contam com profissionais de comunicação, os técnico-administrativos, docentes e estudantes mandam notícias ora para a Agência de Notícias, ora para o Núcleo de Divulgação Institucional. Outros Núcleos avaliam o que deve ser enviado para o portal e acreditam manter um relacionamento rotineiro com a Agência de Notícias. Porém, não há uma rotina estabelecida e os critérios do que é publicado também não estão claros, uma vez que nem tudo o que se deseja divulgar de uma unidade vai para as notícias na capa do portal, há uma hierarquia de informações entre os sites da Universidade. Os jornalistas que atuam na Agência de Notícias explicam quais os critérios adotados para essa seleção:

A gente tem diretrizes para isso, em primeiro lugar, temas de interesse público. Tem que atender a uma questão que é de interesse público e interesse privado não deveria nem ir para o site, né! [...] Para além disso, existe uma série de valores-notícia ${ }^{3}$ que a gente usa para ponderar o que é importante

\footnotetext{
${ }^{2}$ Entende-se por portal um site que aglomera outros sites de mesmo domínio, ou seja ufsm.br.

${ }^{3}$ Os valores-notícia são princípios utilizados pelos meios de comunicação e seus profissionais para definir a potencialidade de um fato tornar-se notícia. Alguns exemplos são: nível hierárquico dos indivíduos envolvidos; o impacto sobre o público; a quantidade de pessoas envolvidas; a relevância das possíveis consequências do fato; interesse; atualidade; qualidade das informações e imagens; exclusividade. (HOHLFELDT, 2011).
} 
e o que não é, como o fato de ser uma notícia que contempla um público mais amplo possível. Então, algo que é restrito só a um grupo pequeno não merece um destaque e daí, muitas vezes, a gente separa isso como notícias para estudantes ou para servidores. [...] A quantidade também de setores envolvidos com aquela situação, a relação com a missão da Universidade, ensino, pesquisa e extensão... quando a gente trabalha questões relacionadas a formas de ingresso, para nós, são questões prioritárias, a gente vai sempre dar espaço (Trecho de entrevista com Jornalista 2).

Quando as notícias passam pelos Núcleos de Divulgação Institucional, a rotina de edição e publicação é muito similar às da Agência de Notícias. Nos Núcleos onde há um jornalista atuando, a rotina prevê entrevistas, busca de informações, edição e publicação de reportagens mais elaboradas. Nos Núcleos que contam com bolsistas de Jornalismo, estes concentram o trabalho de pesquisa e reportagem, deixando para os Relações Públicas ou servidores de outras áreas a edição e publicação das notícias.

A partir das entrevistas e da observação participante, diversos problemas foram identificados no processo de produção de conteúdo para o portal/site da UFSM. Alguns problemas identificados e melhorias propostas vão além do redesenho do processo em si, mas dizem respeito à estrutura e à rotina de trabalho, normativas e sistemas. Os problemas e suas respectivas propostas de melhorias são apresentados no Quadro 2.

\subsection{Problemas no fluxo de informação, retrabalho e limite de tarefas confuso}

A UFSM é uma organização complexa, com diversos órgãos, centros de ensino, colégios, campi fora de sede, o que dificulta o fluxo de informações de forma que todas as informações cheguem a todos. Além disso, por haver equipes de comunicação centralizadas na Coordenadoria de Comunicação para atender toda a Universidade e profissionais descentralizados em algumas unidades, por vezes o limite de tarefas fica confuso. Até o lançamento da Política de Comunicação em 2018, o único documento que regrava a área era o Regimento Interno da Universidade (UFSM, 2011) que apenas define as funções da Coordenadoria, não mencionando diretrizes para outros setores. De acordo com os próprios profissionais:

\begin{abstract}
Muitas vezes tinha dois setores fazendo a mesma pauta, por exemplo, uma notícia, no fim de um evento e tu tinha dois, três setores, às vezes, trabalhando no texto sobre aquilo quando é só a gente conversar e aí saber que alguém já estava fazendo, beleza! Podia direcionar esse recurso humano para fazer outra reportagem (Trecho de entrevista com Jornalista 1).
\end{abstract}

A falta de conhecimento sobre o que pode ou não se tornar notícia ou quais as informações necessárias para sua publicação geram retrabalho para a Agência na apuração e edição das informações. Isso ocorre, muitas vezes, porque em muitos órgãos e unidades, os profissionais que atuam como comunicadores não são da área.

Quadro 2 Sínteses dos problemas e melhorias sugeridas no processo de produção de conteúdo para o portal/site da UFSM

\begin{tabular}{|c|c|}
\hline Problemas & Melhorias Sugeridas \\
\hline $\begin{array}{l}\text { - Retrabalho } \\
\text { - Problemas no fluxo de informação } \\
\text { - Limite de tarefas confuso }\end{array}$ & $\begin{array}{l}\text { - Padronização dos processos e definição de tarefas de cada setor } \\
\text { - Conhecimento prévio do formato de notícia, treinamentos } \\
\text { - } \text { Formulário para envio de notícias e solicitação de trabalhos de Comunicação } \\
\text { - } \text { - Sistema integrado para organização e planejamento de atividades } \\
\text { - Reuniões de pauta }\end{array}$ \\
\hline $\begin{array}{l}\text { - Critérios de divulgação não definidos } \\
\text { - Interesses particulares e pressões hierárquicas }\end{array}$ & $\begin{array}{l}\text { - Guia de produção de conteúdo e de critérios para publicação de notícias } \\
\text { - Treinamentos periódicos }\end{array}$ \\
\hline $\begin{array}{l}\text { - Pouca divulgação científica } \\
\text { - Dificuldade de popularizar a linguagem das } \\
\text { pesquisas } \\
\text { - Falta de relacionamento com os professores } \\
\text { - Desvalorização da Comunicação enquanto } \\
\text { área técnica }\end{array}$ & $\begin{array}{l}\text { - Educação para a mídia, valorização e reconhecimento da área de Comunicação } \\
\text { - Retorno dos resultados de divulgação para os pesquisadores } \\
\text { - Ronda pelos sites e nos setores } \\
\text { - } \text { Banco de fontes } \\
\text { - Exigências de popularização da ciência pelos fundos de investimentos em projetos de } \\
\text { ensino, pesquisa e extensão }\end{array}$ \\
\hline
\end{tabular}

Fonte elaborado pelas autoras (2018) com base nas entrevistas aplicadas entre setembro e outubro de 2018. 
Acho que a Agência, muitas vezes, não consegue produzir mais conteúdo porque leva muito tempo editando conteúdo, reescrevendo, sabe! Claro, não tem como exigir que pessoas que não sejam da área produzam uma notícia exatamente no formato que a gente espera e tudo mais, mas no momento, a gente tem profissionais de comunicação centralizados, alguns espalhados pelas unidades e, por isso, a gente percebe a diferença nos setores onde tem um profissional de comunicação (Trecho de entrevista com Jornalista 1).

Para sanar esses problemas, já houve uma iniciativa conjunta do Gabinete do Reitor e Agência de Notícias de criar um Banco de Pautas, uma planilha compartilhada no Google Drive com questões como: origem da pauta, resumo, tipo de pauta (institucional, pesquisa, extensão...), jornalista responsável, fonte para mais informações. Uma tentativa mais recente tem utilizado o sistema Trello ${ }^{4}$ para organização conjunta de pautas e grandes reportagens.

Porém, duas questões são anteriores a isso. A primeira é a necessidade de uma padronização de processos para que todos utilizem o sistema. A segunda é a organização de treinamentos constantes tanto de utilização do sistema, como do formato ideal de notícia para o site da UFSM - o que caracteriza uma notícia que deve ser enviada aos jornalistas da Agência de Notícias, ou seja, uma notícia que será publicada na capa do portal da UFSM.

A sistematização poderia ainda ser ampliada, desde o envio da notícia a partir de um formulário no site. No site anterior, havia dois formulários disponíveis: "Envie sua notícia" e "Divulgue seu evento". Desde o lançamento do novo portal da UFSM, em julho de 2018, eles estão sendo revistos pela equipe que desenvolve o site. Outros setores da Universidade, como a Pró-reitora de Infraestrutura (Proinfra) e o Centro de Processamento de Dados (CPD) já utilizam um sistema aberto de solicitação e acompanhamento de serviços, customizado pela UFSM, que facilita a delegação e o retorno aos solicitantes diante da alta demanda por serviços.

Outra iniciativa importante são as reuniões de pauta periódicas. Recentemente, elas foram retomadas semanalmente entre Agência de Notícias e Gabinete do Reitor. Porém, seria ideal incluir semanalmente os demais veículos da Universidade: TV Campus e Rádios Universidade AM e UniFM. Além disso, trimestralmente, seria estratégico ampliar as reuniões de pauta com os Núcleos de Divulgação Institucional e Unidade de Comunicação Integrada, de forma a antecipar-se a alguns acontecimentos, planejar as ações de comunicação e sempre relembrar a necessidade do uso do sistema para organização conjunta da produção de conteúdo.

\subsection{Critérios de divulgação não definidos, interesses particulares e pressões hierárquicas}

Embora para os jornalistas da Agência de Notícias estejam claros quais são os critérios e valores-notícia necessários para uma notícia ocupar a capa do portal da UFSM, para os demais comunicadores isso ainda gera dúvidas. Principalmente, para aqueles que atuam na produção de conteúdo sem ter formação na área ou qualquer treinamento complementar. Para professores, técnico-administrativos e estudantes, esses critérios são ainda mais desconhecidos. A falta de um guia com critérios definidos e aprovados por uma instância superior à Agência de Notícias também faz com que muitas vezes pressões hierárquicas antecipem interesses particulares ao interesse público.

Já existe um Guia de Notícias utilizado internamente pelos jornalistas da Agência, ele necessita de remodelação para focar mais na produção de conteúdo e menos na questão linguística, mas pode ser ampliado, publicado para toda a comunidade acadêmica e utilizado em treinamentos periódicos para servidores que atuam nos núcleos de divulgação das unidades e órgãos, conforme explicita o Jornalista 1.

A gente tem um Guia ali da Agência, mas hoje ele é mais técnico, traz mais, tipo questões de estilo de texto. Hoje ele é para uso interno da Agência. Acho que a gente precisa padronizar isso e precisa compartilhar com todo mundo que produz conteúdo para os seus próprios sites e para quem manda informações porque, assim a gente consegue ter um controle das notícias que estão na página principal da Universidade. Existem muitos servidores que publicam notícias nos seus próprios sites e que não têm jornalistas ou outros profissionais de comunicação e que, muitas vezes, não têm essa noção que a gente tem né, que já é algo que a gente, enfim, traz da formação, mas que também tem esse documento que padroniza minimamente o tipo de conteúdo que a gente publica. [...]. No momento em que a gente tem um documento que seja aprovado pelo próprio Comitê [da Política de Comunicação], isso facilita tanto para os produtores de conteúdo produzirem

${ }_{4}^{4}$ O Trello é uma ferramenta web gratuita de gerenciamento de projetos em listas que pode ser utilizada para organizar tarefas de trabalho. 
seu próprio material, publicar em seu próprio site, quanto para mandarem para a Agência, evitando um retrabalho da Agência de ter que editar de novo um texto que já foi editado, mas que não está padronizado. E até para realmente ficar mais claro o que vai para o site (Trecho de entrevista com Jornalista 1).

\subsection{Pouca divulgação científica, dificuldade de popularizar a linguagem das pesquisas, falta de relacionamento com os professores, desvalorização da área de Comunicação}

Os documentos da Universidade, inclusive o próprio PDI, ainda são muito focados na comunicação institucional. Os profissionais que atuam na comunicação também contam que muito do seu dia a dia está voltado para a cobertura de eventos, não dedicando muito do seu tempo à divulgação de atividades de pesquisa e extensão. Apenas a Revista Arco é especializada no jornalismo científico, capaz de "traduzir" e simplificar a linguagem científica, tornando-a acessível para toda a população. Somado a isso, há uma desvalorização da comunicação enquanto área técnica, de acordo com o Jornalista 2, alguns professores são arrogantes e acham que entendem de comunicação, subvalorizam a área e creem que qualquer um pode escrever notícias, ou seja, muitas vezes não respeitam a orientação dos profissionais de comunicação, como ajustes em textos ou utilização de canais específicos para divulgação de determinado tema.

Uma educação para a mídia seria necessária, ou seja, uma campanha para toda a comunidade universitária que dissemine a importância da comunicação pública, principalmente em suas perspectivas governamental e científica, e o papel do comunicador, valorizando o conhecimento técnico da área. Há diversos eventos da Universidade voltados aos servidores, como Seminário de Integração de Novos Servidores, Semana do Servidor Público e Seminário de Liderança Lidere, em que a temática comunicação pública poderia ser aprofundada. Além disso, uma ronda periódica (semanal, quinzenal ou mensal) pelos sites, setores, laboratórios e grupos de pesquisa também poderia estabelecer um maior relacionamento entre comunicadores e pesquisadores/ extensionistas.

Ainda no processo de produção de conteúdo para o site, uma simples mudança seria dar retorno aos professores e técnicos sobre suas pautas. Tanto as que não são publicadas na capa do portal explicando os critérios de seleção (isso já faria parte da citada educação para a mídia), como também as que são publicadas ou enviadas para a imprensa. Além de estreitar o relacionamento e gerar confiança, isso traria transparência para o processo de comunicação. Uma fonte que recebe retorno entende e confia na comunicação da instituição, tem potencial para ser fonte em outros momentos e para indicar outras potenciais fontes de conteúdo qualificado.

Um Banco de Fontes está sendo iniciado na Universidade. O documento reúne o contato dos professores, área de atuação, grupos de pesquisa e principais projetos para que possa ser consultado sempre que necessário pelos profissionais de comunicação da Universidade ou mesmo pela imprensa em necessidade de entrevista ou de esclarecimento de informações sobre determinado assunto. Quando finalizado, esse documento agilizará muito o trabalho da equipe e, conforme mencionou o Jornalista 1, seu processo de construção permitirá uma aproximação entre profissionais de comunicação e pesquisadores/ extensionistas.

Por fim, numa perspectiva mais macro de gestão universitária, poderia ser exigido a todos os projetos submetidos aos Fundos de Incentivo ao Ensino (Fien), Pesquisa (Fipe) e Extensão (Fiex) uma contrapartida de divulgação científica, tecnológica ou artística, por meio de notícia, vídeo, publicação nas mídias sociais ou evento aberto ao público dos resultados dos projetos selecionados. Divulgação essa, na perspectiva da comunicação científica e da popularização da ciência. O edital Fiex publicado em março de $2018^{5}$ já prevê algo nesse sentido, mas que pode ser ampliado:

\footnotetext{
9.2 A ação aprovada neste edital está automaticamente sujeita a participar das ações do Programa Visibilidade, Programa Institucional sob coordenação da Pró-reitora de Extensão, que visa a promover e divulgar jornalística e cientificamente $\mathrm{s}$ ações de extensão desenvolvidas na UFSM.
} 
Isso geraria um compromisso dos pesquisadores/extensionistas e facilitaria o trabalho dos comunicadores e/ou jornalistas externos.

\subsection{Propostas de melhorias e redesenho do processo}

A melhoria e o redesenho de processos nem sempre consistem na informatização do processo. Muitas vezes, uma reorganização no trabalho, melhor redistribuição das tarefas e manuais de padronização já cumprem o objetivo. Porém, para este estudo, a proposta é a adaptação de um sistema já utilizado na UFSM, o OTRS ${ }^{6}$, para solicitação e acompanhamento de serviços de comunicação. Atualmente, a Coordenadoria de Comunicação e os Núcleos de Divulgação Institucional já utilizam diversos sistemas de forma a facilitar seu trabalho, porém todos estão desconectados. As solicitações de notícias ou divulgação de eventos são enviados por e-mail ou por formulário no site (em fase de reformulação no novo portal); as pautas são compartilhadas e organizadas por planilha online no Google Drive ou no Trello; a atualização do site é realizada pelo Wordpress ${ }^{7}$; alguns setores enviam newsletter ao público com as principais notícias da semana pelo Mail Chimp ${ }^{8}$. Por isso, propõe-se um sistema que unifique as operações, facilite as solicitações e agilize os retornos de forma a integrar o trabalho em equipe, rompendo distâncias geográficas e setoriais, tornando o processo mais fluído, padronizado e transparente aos usuários.

O princípio é a reativação do formulário "Envie sua notícia” no site, porém já interligado ao sistema OTRS. As sugestões de campos e informações: Nome, E-mail, Setor, Título da Notícia, Corpo da Notícia, Desafio organizacional do PDI que atende, contato para mais informações.

O próprio formulário já traria informações instrutivas para a produção de conteúdo, facilitando o trabalho do usuário, fortalecendo os treinamentos periódicos e as dicas do Guia de Produção de Conteúdo sugerido a seguir. Além disso, o formulário traria os desafios do PDI, de forma a alinhar a publicação de notícias ao planejamento estratégico da UFSM.
A solicitação de notícia entraria como demanda para a Agência de Notícias ou algum dos Núcleos de Divulgação Institucional, de acordo com o setor selecionado pelo usuário. A partir daí o comunicador executaria o processo conforme demonstrado na Figura 2. Pelo sistema, seria possível realizar a delegação e organização de pautas entre setores - da Agência para os Núcleos e vice-versa - bem como seu acompanhamento. Caso a notícia não possa ser publicada na capa do portal por não se enquadrar nos critérios estabelecidos, uma notificação seria enviada ao solicitante contribuindo na educação para a mídia e na transparência do processo. Quando da sua publicação, uma notificação seria enviada com o link da notícia, assim o usuário teria a certeza de que as informações enviadas foram publicadas, sendo estimulado a visitar o site.

O sistema poderia ainda ser utilizado para solicitação de outros serviços de comunicação, como: divulgação e organização de eventos; produção audiovisual; participação em programas de rádio; revisão de cerimoniais; apoio em planejamento de comunicação; criação de peças gráficas e campanhas publicitárias; conforme já ocorre em outras universidades.

Além da informatização, propõe-se a construção de alguns documentos de comunicação. Um deles, o Banco de Fontes, poderá ser consultado durante o processo, principalmente nas reuniões de pauta semanais entre todos os setores ou quando necessário aprofundar informações sobre determinado tema. $\mathrm{O}$ outro, já existente, consiste em um Guia de Produção de Conteúdo, que poderia ser reformulado, aprovado e publicado pelo Comitê da Política de Comunicação. Abaixo, uma proposta de sumário para esse Guia: 1) Veículos de comunicação da UFSM: sites, mídias sociais, TV, Rádios, e-mail, comunicação dirigida, assessoria de imprensa; 2) Hierarquia da informação do portal/site da UFSM; 3) Critérios para publicação de notícias no portal da UFSM; 4) Dicas de produção de conteúdo: título, padronização de linguagem, informações necessárias, coesão, imagens, acessibilidade, alinhamento ao PDI.

Nessa proposta de melhoria, a partir da necessidade da comunidade universitária de divulgar

\footnotetext{
${ }^{6}$ Sistema aberto de gestão de serviços, fluxos de trabalho e notificações, mantido pelo OTRS Group

7 Software livre de gerenciamento de conteúdo web, principalmente para a criação de sites e blogs.

${ }^{8}$ Plataforma de automação de e-mail marketing.
} 
Gestão de Processos de Comunicação em Instituições Federais de Ensino Superior: Um Estudo de Campo na Universidade Federal de Santa Maria

Figura 3 Processo de atualização do portal/site da UFSM com sugestão de melhorias

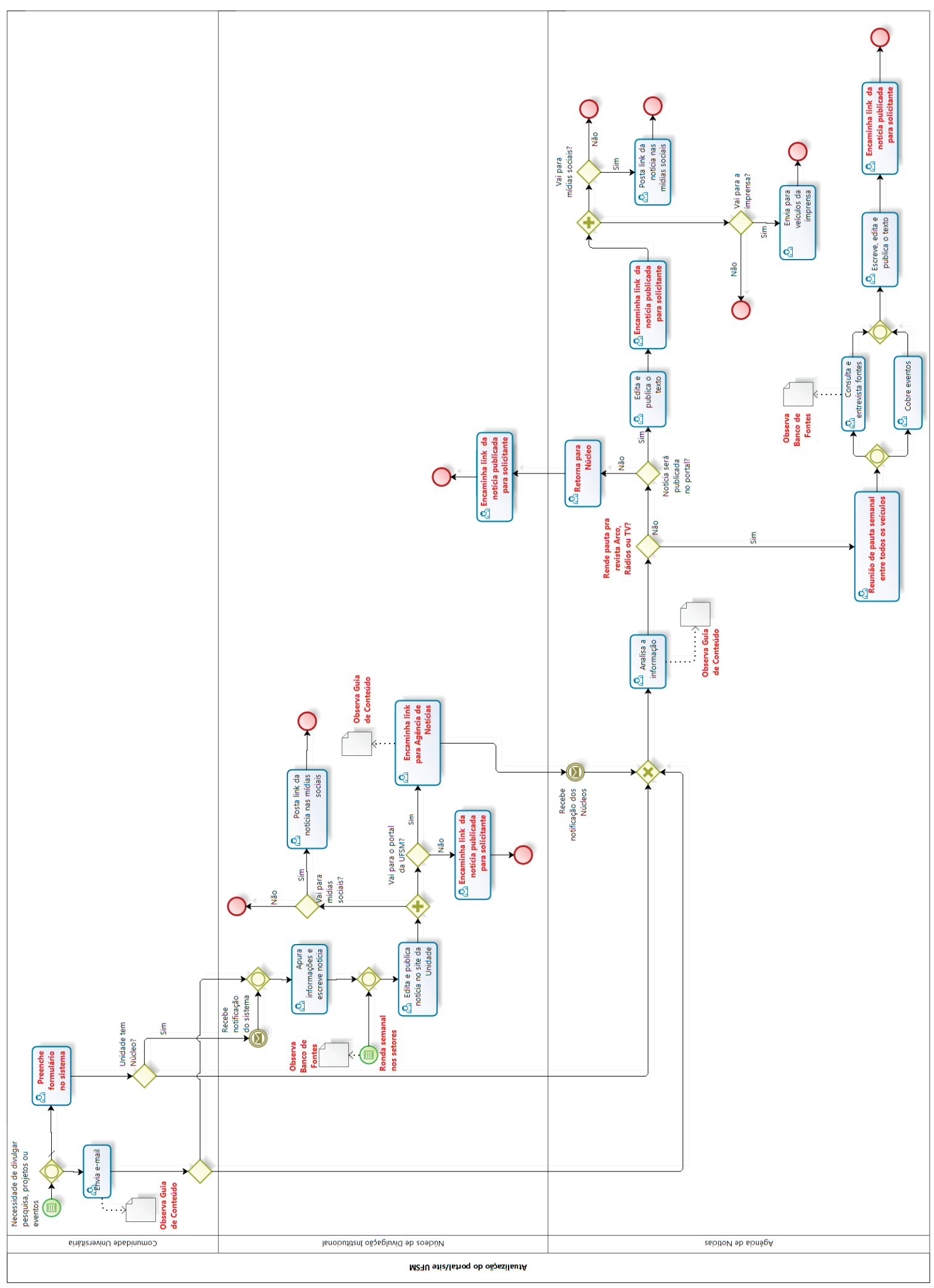

Fonte elaborada pelas autoras (2018) no software Bizagi Modeler, com base em entrevistas semiestruturadas realizadas entre setembro e outubro de 2018. 
alguma pesquisa, projeto ou evento, o processo padrão é preencher o formulário "Envie sua notícia" no site. Caso a Unidade do solicitante tenha Núcleo de Divulgação Institucional, o sistema envia a demanda diretamente para o Núcleo que recebe a notificação; apura as informações; escreve e publica a notícia. $\mathrm{Ou}$ ainda, publica a notícia a partir das rondas semanais nos setores. Após, decide se a notícia será publicada nas mídias sociais e/ou se será enviada para a Agência de Notícias para publicação no portal. Se a notícia vai para o portal, o Núcleo encaminha a demanda via OTRS para a Agência. Se não, encerra o serviço, retornando ao solicitante com o link da notícia publicada no site da Unidade.

A Agência de Notícias, por sua vez, recebe as informações da comunidade universitária ou de algum Núcleo de Divulgação Institucional via sistema; apura a informação; decide se rende pauta para outro veículo ou para o portal com base no Guia de Produção de Conteúdo. Se rende pauta para o portal, edita e publica o texto; define se será publicado nas mídias sociais e/ou se será enviado para a imprensa; encerra o serviço no sistema enviando link da notícia publicada no portal para o solicitante.

Caso a notícia renda pauta para outro veículo, é levada para a reunião de pauta semanal. Para o aprofundamento de informações com entrevistas, é possível consultar o Banco de Fontes.

Conforme orienta a ABPMP (2009), uma das formas de documentar oportunidades de melhoria é mapeando os processos como eles são realizados no momento da análise (as is) e propondo as melhorias necessárias a partir dos problemas identificados, redesenhando o processo como ele deveria ser (to be). O processo de atualização do portal/site da UFSM foi mapeado como ocorre atualmente (as is) pelo Grupo de Modernização Administrativa da UFSM (Figura 1); redesenhado (to be) com sugestões de melhorias no redesenho do processo (Figura 2).

\section{CONCLUSÕES E RECOMENDAÇÕES}

Os documentos de comunicação da Universidade apontam uma preocupação ainda maior com a comunicação institucional, para organização da área e fortalecimento da imagem institucional. Isso é um reflexo do recente lançamento da Política de Comunicação, primeiro documento que reconhece todos os setores e desenha diretrizes sobre a atuação profissional na área. A preocupação com a comunicação governamental é expressa na necessidade de dar transparência à gestão e tornar os veículos de comunicação mais acessíveis, seguindo as leis e normativas do governo. A comunicação científica coloca-se como importante, porém ainda indica como aprofundar o relacionamento entre comunicadores e professores pesquisadores/extensionistas.

Para atender ao objetivo de identificar os processos de comunicação já mapeados e institucionalizados na UFSM, foram estudados alguns formulários aplicados pelo Grupo de Modernização Administrativa da Universidade junto à Coordenadoria de Comunicação que identificaram os processos de Comunicação institucional; Atualização do portal/site; Mídias sociais; Assessoria de imprensa; Produção da Revista Arco; Produção de conteúdo radiofônico para as Rádios e Produção de conteúdo audiovisual para TV.

Buscando ampliar o mapeamento de um processo a partir da perspectiva de outros setores de comunicação da Universidade, os Núcleos de Divulgação Institucional, foi escolhido o processo de Atualização do site/portal da UFSM por ser um dos mais comuns em todas as IFES, por abranger aspectos da comunicação pública e por envolver diversos públicos da instituição. Na identificação de problemas e gargalos no processo, o estudo apontou deficiências no fluxo de informação; limite de tarefas confuso entre os setores e retrabalho; critérios de divulgação de notícias não definidos com sobreposição de interesses particulares e pressões hierárquicas; pouca divulgação científica e dificuldade de popularizar a linguagem das pesquisas; falta de relacionamento com os professores; desvalorização da Comunicação enquanto área técnica.

A partir disso, o processo foi redesenhado, sugerindo a utilização de um formulário para envio de notícias e do sistema OTRS para delegação e acompanhamento das demandas de comunicação, desde o recebimento até o retorno final ao solicitante. $\mathrm{O}$ novo processo também prevê uma ronda periódica pelos sites e setores em busca de notícias, bem como reuniões de pauta semanais entre todos os veículos 
de comunicação da instituição. As propostas de melhorias ainda incluem a construção de um Banco de Fontes com contatos e projetos dos professores e a remodelação e publicação de um Guia de Produção de Conteúdo.

Além do redesenho do processo, o estudo propõe reuniões permanentes de planejamento entre todos os setores de comunicação; treinamentos periódicos para produção de conteúdo, principalmente para os servidores que atuam na área sem formação técnica; campanhas de valorização da comunicação pública e da área de comunicação; educação dos professores para a popularização da ciência; exigências de comprovação de divulgação e popularização de projetos de ensino, pesquisa e extensão financiados pela Universidade.

A proposta de padronizar e informatizar esse processo de comunicação não objetiva engessar o processo, nem o tornar impessoal, muito pelo contrário. A integração das práticas de gestão por processos e comunicação pública neste estudo tem como foco sistematizar as ações do dia a dia, de forma que os profissionais possam ter mais tempo para planejamento e antecipação das demandas, bem como para relacionamento com as fontes e aprofundamento das pautas. As melhorias também visam a uma profissionalização no trabalho de comunicação pública, principalmente em suas perspectivas governamental (indo além do exigido em leis e normas do governo) e científica (cumprindo o compromisso social das IFES de popularizar a ciência). Além disso, a busca pela eficiência e eficácia em um processo comum a todos os setores de comunicação de IFES contribui com a prática profissional num período em que a qualidade do ensino das universidades está posta à prova.

No que diz respeito ao campo teórico, a integração dessas duas áreas - comunicação pública e gestão por processos - não é comum, apenas um estudo anterior foi encontrado, conduzido por Silva em 2014 no IFSC. Por isso, este trabalho tem grande contribuição científica, tanto para a comunicação pública quanto para a administração pública.

\section{REFERÊNCIAS}

ABPMP - ASSOCIATION OF BUSSINESS PROCESS MANAGEMENT PROFESSIONALS (2009). Guia para o Gerenciamento de Processos de Negócio: Corpo Comum de Conhecimento. [S.l].

\section{BARICHELLO, E. M. da R. Comunicação e comu- nidade do saber. Santa Maria: Palotti, 2001.}

BASTOS, F. C. P. Proposta de Mapeamento e Melhoria de Processo de Importação: Um Estudo de Caso. Dissertação (Curso de Mestrado em Sistemas de Gestão) - Universidade Federal Fluminense, Niterói, RJ, 2013.

\section{BRANDÃO, E. P. (2012). Conceito de comunicação} pública. In: DUARTE, J. (Org.), Comunicação pública: Estado, mercado, sociedade e interesse público (pp. 1-34). São Paulo: Atlas.

BRASIL. INSTITUTO DE PESQUISA ECONÔMICA APLICADA - IPEA. (1996b). Ministério do Planejamento e Orçamento. Passos para o Gerenciamento Efetivo de Processos no Setor Público: Aplicações Práticas. Brasília: jun. 1996b. Disponível em: <http://www.ipea.gov.br/pub/td/ td_427.pdf $>$. Acesso em: 30 abr. 2018.

BRESSER-PEREIRA, L. C. (1998). Reforma do Estado para a cidadania: a reforma gerencial brasileira na perspectiva internacional. São Paulo: Editora 34; Brasília: ENAP.

BRESSER-PEREIRA, L. C.; SPINK, P. (2001). Reforma do Estado e administração pública gerencial. Rio de Janeiro: FGV.

DAVENPORT, T. H. (1994). Reengenharia de Processos: como inovar na empresa através da tecnologia da informação. Rio de Janeiro: Campus.

FERREIRA, V. C. et al. (2014). Contribuições do Gerenciamento de Processos para a Administração Pública Mineira. Reuna, Belo Horizonte - MG, Brasil, v.19, n.1, p.5-28, Jan. a Mar. 2014 - ISSN 2179-8834. 
FERREIRA, C. M. M. (1999). Crise e Reforma do Estado: uma questão de Cidadania e valorização do servidor. In: PETRUCCI, V. \& SCHWARZ, L. (Orgs.). Administração Pública Gerencial: a reforma de 1995. Brasília: EdUnB.

GIL, A. C. (1999). Métodos e técnicas de pesquisa social. $5^{\mathrm{a}}$ ed. São Paulo: Atlas.

GONÇALVES, J. E. L. (2000). As empresas são grandes coleções de processos. Revista de Administração de Empresas, São Paulo, v. 40, n. 1, p. 6-19, jan/mar. 2000.

. (2000a). Processo, que processo? Revista de

Administração de Empresas, São Paulo, v. 40, n. 4, p. $8-19$, jan/mar.

KUNSCH, M. M. K. (2003). Planejamento de Relações Públicas na comunicação integrada. São Paulo: Summus, 2003.

MARCHIORI, M. Comunicação interna: um fator estratégico no sucesso dos negócios. In: MARCHIORI, M. (org.) Faces da cultura e da comunicação organizacional. 2. Ed. - São Caetano do Sul, SP: Difusão Editora, 2008. p. 207-224.

MELLO, C. H. P. et al. (2006). ISO 9001:2000: sistema de gestão da qualidade para operações de produtos e serviços. São Paulo: Atlas.

PALUDO, A. V. (2012). Administração pública: teoria e questões. Rio de Janeiro: Elsevier.

SILVA, F. F. B. (2014). Redesenho da estrutura organizacional na perspectiva do mapeamento de processos: análise e proposição para a área de comunicação do Instituto Federal de Santa Catarina (IFSC). Dissertação (Mestrado Profissional em Administração) - Universidade do Estado de Santa Catarina. Disponível em: <http://tede.udesc.br/handle/handle/646> Acesso em: 07 abr. 2018.

SMART, P. A. et al. Understanding Business Process Management: implications for theory and practice. British Journal of Management, v. 20, p. 491-507, 2009.
UNIVERSIDADE FEDERAL DE SANTA MARIA (UFSM). (2018). Resolução no 005 de 16 de abril de 2018. Aprova a Política de Comunicação da Universidade Federal de Santa Maria. Disponível em: <http://site.ufsm.br/arquivos/uploaded/uploads/320a27dd-2264-4104-92ef-501c34734b9d.pdf > Acesso em: 24 abr. 2018.

(2011). Regimento Geral da Universidade

Federal de Santa Maria. Aprovado pelo Parecer 031/2011 da Comissão de Legislação e Regimentos do Conselho Universitário e Resolução no 006/2011, de 28 abril de 2011. Disponível em: <http://site.ufsm. br/arquivos/uploaded/arquivos/7a09d209-53a6-49a7-90c7-b99c7d82c16b.pdf>. Acesso em: 24 jan. 2018. (2016). Plano de Desenvolvimento Institucional 2016-2026. Santa Maria. Disponível em: http://site.ufsm.br/arquivos/uploaded/uploads/ d23d5289-4212-4ccb-8b90-21a02e588e21.pdf > . Acesso em: 24 jan. 2018.

VALLE, R.; OLIVEIRA, S. B. (2009). Análise e Modelagem de Processos de Negócio: Foco na Notação BPMN. São Paulo: Atlas.

WEBER, M. H. (2007). Na comunicação pública, a captura do voto. LOGOS 27: Mídia e democracia. Disponível em: <http://www.e-publicacoes.uerj.br/ index.php/logos/article/view/12464> Acesso em: 10 out. 2017.

ZÉMOR, P. (2009). Como anda a comunicação pública? Revista do Serviço Público. Disponível em: $<$ https://revista.enap.gov.br/index.php/RSP/article/ view/21> Acesso em: 10 out. 2017. 